\title{
Angiocholitis due to Hydatid Cyst of the liver fistulized in the bile ducts: Comparative study between surgical treatment and endoscopic treatment
}

Omar Marghich (D Omar.marghich@gmail.com )

Centre Hospitalier Universitaire Hassan II

Amine Hamdane

Centre Hospitalier Universitaire Hassan II

Tarek Anis

Centre Hospitalier Universitaire Hassan II

Mohamed Alila

Centre Hospitalier Universitaire Hassan II

Abdelmalek ousadden

Centre Hospitalier Universitaire Hassan II

Khalid Ait Taleb

Centre Hospitalier Universitaire Hassan II

Sidi Adil Ibrahimi

Centre Hospitalier Universitaire Hassan II

dafr-allah benajah

Centre Hospitalier Universitaire Hassan II

Khalid Mazaz

Centre Hospitalier Universitaire Hassan II

\section{EL Bachir Benjelloun}

Centre Hospitalier Universitaire Hassan II

\section{Research Article}

Keywords: Angiocholitis, Bilio cystic fistula, ERCP, Surgery

Posted Date: May 14th, 2021

DOl: https://doi.org/10.21203/rs.3.rs-461214/v1

License: (c) (1) This work is licensed under a Creative Commons Attribution 4.0 International License. Read Full License 
Page 2/11 


\section{Abstract}

Background:

Liver hydatid is a parasitic disease considered benign but can become dangerous because of its complications. The fistula in biliary tract remains one of the most feared complications by its frequency, morbidity and mortality.

Materials and methods:

We present a descriptive and comparative retrospective study at the university hospital Hassan II of Fez. This study was carried out on 63 cases of angiocholitis on hydatid cyst of the liver fistulized in the bile ducts and extends over a period of 5 years from January 2015 to December 2019. The objective of this study is to evaluate and compare the contribution of different therapeutic modalities in the treatment of cystic biliary fistula (Surgical treatment against endoscopic treatment).

Results:

Surgical treatment was used in 22 patients against 41 patients who underwent endoscopic treatment. The success rate of endoscopic treatment was higher than that of surgical treatment (83\% against $73 \%$, $p=0.350$ ). The mortality rate was reduced in the endoscopy group compared with patients in the surgery group ( $5 \%$ against $14 \%, p=0.226)$. General morbidity and major morbidity were higher significantly in patients treated surgically (General morbidity: surgery $41 \%$ against $2 \%$ for endoscopy, P0.05

Conclusion:

Endoscopic treatment should be considered as the treatment of choice for angiocholitis due to hydatid cyst of the liver fistulized in the bile ducts.

\section{Background}

Hydatid cyst of the liver is a parasitic disease caused by Echinococcus granulosus. It is considered as an endemic disease in most parts of the world, especially in the Mediterranean where sheep husbandry is common, and remain an important medical health problem in these regions.

Hydatidosis may remain asymptomatic for a long time, but can also cause serious complications. Common complications of hydatid cyst of the liver include rupture into intrahepatic bile ducts or the peritoneal cavity, invasion of other organs, pressure on the biliary tree and other neighboring structures, and infection. Of these, communication between the cyst and the biliary tree is the most common and serious complication.

Although surgery is the classic method of treating bilio cystic fistula, endoscopic retrograde cholangiopancreatography (ERCP) has emerged as an alternative choice for the management of those 
complications.

\section{Methods}

Our series is a retrospective descriptive and comparative study, performed at the department of general surgery, gastroenterology and intensive care unit of the university hospital Hassan II in Fez. This study covers a period of 5 years from January 2015 to December 2019.

In this study we included all patients admitted for angiocholitis due to a Cyst biliary communication confirmed by ultrasound or CT scan and having undergone surgical or endoscopic treatment. We excluded angiocholitis due to a compressing of the bile ducts, uncomplicated hydatid cyst, hydatid cyst with a complication other than bilio-cystic fistula and Incidental discovery of bilio-cystic fistula during hydatid cyst surgery.

We report in this study 63 cases of angiocholitis due to a Cysto-biliary communication which have been divided into two groups:

Group 1: patients who received surgical treatment $(\mathrm{N}=22)$;

Group 2: Patients who received endoscopic treatment $(N=41)$.

The two groups are comparable in terms of age, sex, socio economic status (SES), comorbidity and number of severe angiocholitis. (Table 1)

Table 1 Demographic and clinical variables of patients in each group

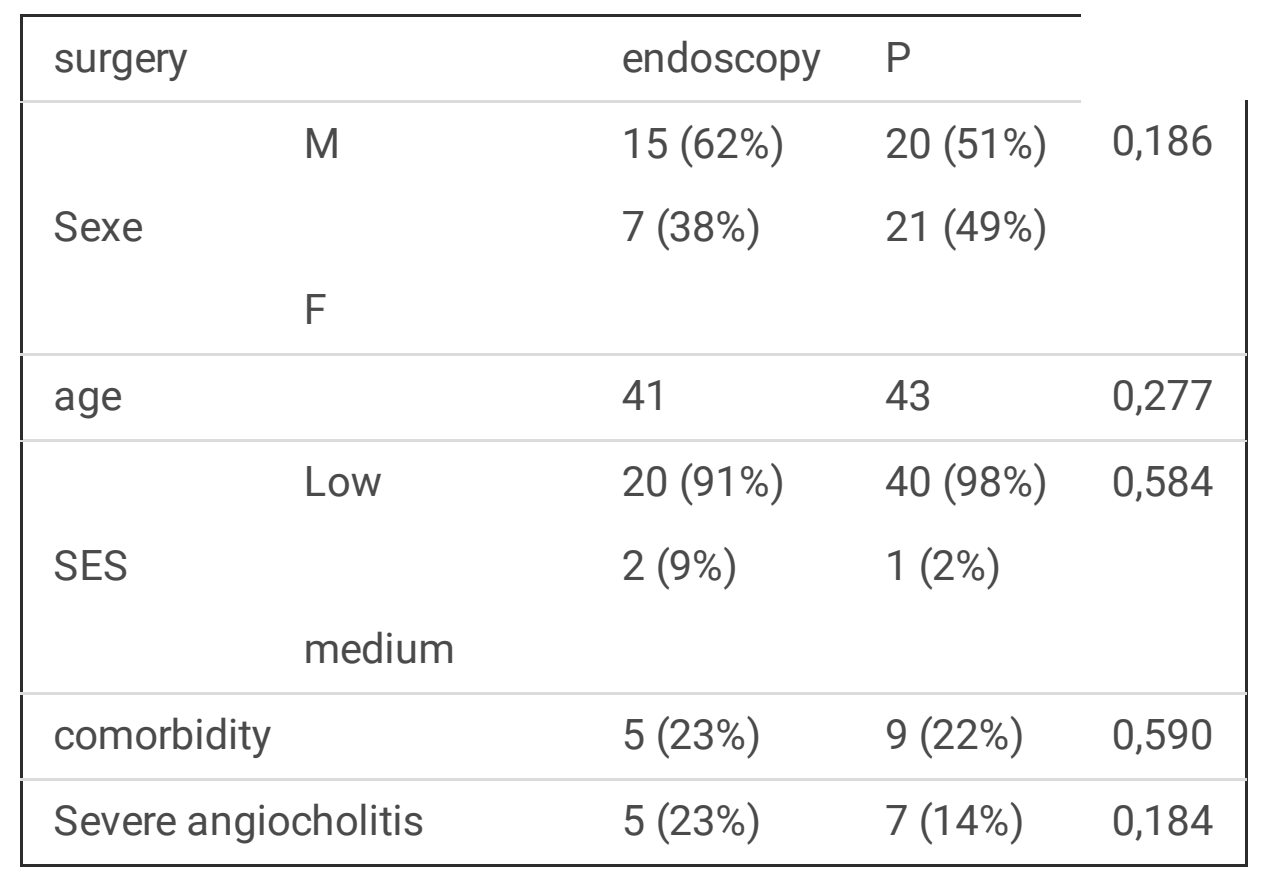

The parameters evaluated were: mortality, morbidity, length of the hospital stay and treatment success defined by the non-necessity of a complementary endoscopic or surgical gesture after the initial 
treatment.

\section{Results}

We report in this study 63 cases of angiocholitis due to hydatid cyst fistula among 264 cases of hydatid cyst of the liver admitted in our institute within a period of 5 years $(24 \%)$.

The mean population age in the study is 42 years (range 17-88 years). Our patients were divided into 35 men (56\%) and 28 women (44\%). The majority of our patients came from rural areas (51 patients, $81 \%$ ), compared to only 12 from urban areas (19\%), and 59 of our patients had a low socio-economic level (95\%). 9 of our patients already had a history of hepatic or pulmonary hydatid cyst (14\%). Diabetes and high blood pressure were the most common comorbidities (16\% and $12 \%$, respectively).

Hepatobiliary ultrasonography was performed in all our patients. Bilio-cystic fistula was detected in 51 cases $(80 \%)$. CT scan was performed on 34 patients, (53\%); it showed a cyst-biliary fistula in all patients. (Table 2)

Table 2 Morphological characteristics on ultrasound 


\begin{tabular}{|ll|}
\hline Morphological characteristics & Number of cases (percentage) \\
Hydatid cyst size & $31(48 \%)$ \\
$\geq 10 \mathrm{~cm}$ & $32(52 \%)$ \\
\hline Number of hydatid cyst & $52(83 \%)$ \\
Unique & \\
multiple & \\
\hline Location & \\
Right lobe & $35(56 \%)$ \\
Left lobe & $18(28 \%)$ \\
both & $10(16 \%)$ \\
\hline Radiological stage & \\
I & $3(5 \%)$ \\
II & $7(11 \%)$ \\
III & $34(55 \%)$ \\
IV & $17(26 \%)$ \\
V & $2(3 \%)$ \\
\hline Suspicion of cysto-biliary fistula & $51(80 \%)$ \\
\hline
\end{tabular}

In group 1, the surgical approach was made by a right costal Laparotomy in $95 \%$ of the cases (21/22) and a median sus-ombilical Laparotomy in a single patient. The treatment of bilio-cystic fistula was done by direct sutures in $18 \%$ of the cases (4/22), Bipolar drainage in $41 \%(9 / 22)$ and according to Perdomo technique in $41 \%$ of the cases $(9 / 22)$.

In group 2, All patients underwent sphincterotomy and removal of membranes with the balloon in $81 \%$ of the cases (34/42), with Dormia basket in $10 \%$ of the cases (4/42), extraction with Dormia basket and balloon in $7 \%(3 / 42)$, with a single case of ERCP failure.

The mean postoperative stay for patients who received endoscopic treatment was lower compared to that of the surgical group ( 7 days vs 11 days) with a statistically significant difference $(P<0.05)$.

The mortality of patients in the surgery group was $14 \%$, a higher rate than that observed in patients treated with ERCP, which is $5 \%$ but without a statistically significant difference $(p=0.226)$. 
Post-operative complications were more pronounced in the group of patients who had surgical treatment, with a statistically significant difference $(P<0.05)$. Major complications: persistence of the biliary fistula, observed in 6 cases or $27 \%$, treated by an endoscopic sphincterotomy; Minor complications: surgical wound infection, observed in 3 cases or $14 \%$. In patients treated with ERCP, we had one major complication, hemorrhage ( $2 \%$ of cases). (Table 3 )

Table 3 Post-therapeutic complications

\begin{tabular}{|lllll|}
\hline surgery & endoscopy & P & \\
N=22 cases & N=41 cases & & \\
General morbidity & $41 \%$ & $2 \%$ & $\mathrm{P}<0,05$ \\
& $\mathrm{~N}=9$ & $\mathrm{~N}=1$ & \\
\cline { 1 - 3 } Major morbidity (Grade $\geq 3$ of Clavien-Dindo classification) & $27 \%$ & $2 \%$ & $\mathrm{P}<0,05$ \\
& $\mathrm{~N}=6$ & $\mathrm{~N}=1$ & \\
\hline
\end{tabular}

The success rate for the endoscopic treatment is greater than that of the surgical treatment but without a statistically significant difference $(p=0.350)$. (Table 4$)$

Table 4 Summary table

\begin{tabular}{|llll|}
\hline surgery & endoscopy & $\mathbf{P}$ & \\
$\mathbf{N}=\mathbf{2 2}$ & $\mathbf{N}=\mathbf{4 1}$ & & \\
\hline Success & $73 \%$ & $83 \%$ & 0,350 \\
\hline Mortality & $14 \%$ & $5 \%$ & 0,226 \\
\hline Morbidity & $41 \%$ & $2 \%$ & $<0,05$ \\
\hline Post-operative stay & 11 Days & 7 Days & $<0,05$ \\
\hline
\end{tabular}

\section{Discussion}

Although surgery is the classic method of treating bilio-cystic fistulas, ERCP has emerged as an alternative method that has already shown its effectiveness and safety for this type of complication. ERCP can reduce the postoperative stay and avoid a re-intervention, often difficult and hemorrhagic.

Most of the series published in the literature do not differentiate between complicated and asymptomatic bilio-cystic fistula. In addition, to our knowledge, there have been no studies in the literature comparing both methods (endoscopic vs surgery) which makes the comparison of our results with the literature difficult. 
In the literature, the success rate of endoscopic treatment was between $86 \%$ and $100 \%$ [5] [6] [7] [8], which is consistent with our results ( $83 \%$ success rate). The success rate of surgical treatment was $73 \%$, which joins the results of the literature (success rate between $72 \%$ and 97\%) [1] [2] [3] [9].

For mortality, in the literature the rate is $0 \%$ for endoscopic treatment [10] [4] [5] [6] [11] [8] and varies between $1 \%$ and $4.5 \%$ for surgical treatment [1] [ 12] [2] [13]. In our series, mortality was higher in both groups compared with literature. It could be explained by the cohort of patients studied (angiocholitis).

Surgical treatment has a significant rate of complications ( $41 \%$ of cases), they were more marked by cysto-biliary fistula, present in $27 \%$ of cases, which is consistent with the study of MEDARHRI [1] ( $20 \%$ of cases). Other complications have been reported in the literature, including subphrenic abscess with a rate that varies between $1 \%$ and $8 \%$ [1] [13] [3], and the suppuration of the residual cavity reported by BARAKET [12] in $9 \%$ of cases. For minor complications, they were more marked by infection of the wound (14\%), which is consistent with the ALPER study [9] and the DAALI study [2] (respectively $6.5 \%$ and $6 \%$ ). Complications of endoscopic treatment remain well below those of surgical treatment. In our series we had only one post-endoscopy complication but that was fatal (patient died by hemorrhagic shock). In the literature, post-endoscopy complications were more marked by acute pancreatitis as reported by the MURAT series [8].

The duration of hospitalization varies between 6 and 12 days for endoscopy [14] [10] [4] [5] and 13 and 27 days for surgery [36] [1] [3]. In our series, this rate was 7 days for the endoscopy group, and 11 days for the surgery group; which can, of course, be explained by the low rate of complications after endoscopy

\section{Conclusion}

In the light of our study comparing the two therapeutic techniques (surgery against endoscopy), we can conclude on the effectiveness, the low morbi-mortality, with a post-intervention stay reduced rate of the endoscopic treatment.

\section{Declarations}

\section{Ethics approval and consent to participate.}

The local institutional review board of surgery at the university hospital Hassan II of Fez has approved this retrospective study (Angiocholitis due to Hydatid Cyst of the liver fistulized in the bile ducts: Comparative study between surgical treatment and endoscopic treatment) and also gave its approval for using medical records without patient informed consent (waiver) with the emphasis on patient's confidentiality.

\section{Availability of data and materials}


All data generated or analyzed during this study are included in this published article.

\section{Competing interests}

The authors declare that they have no competing interests.

\section{Funding}

The authors received no specific funding for this study.

\section{Authors' contributions}

BEB, BDA, ISA, OA, MK and ATK have conceived and coordinated the study

BEB has corrected the manuscript.

MO, HA, AT and AM have done the data collection.

MO has done the redaction of the manuscript.

All authors read and approved the final manuscript.

\section{Acknowledgements}

Not applicable.

\section{Consent for publication:}

Not applicable

\section{Statement}

All methods used in this study were carried out in accordance with relevant guidelines and regulations and approved by the head of the division of abdominal surgery and gastro enterology unit in the university hospital Hassan II of Fes, Morocco

\section{Abbreviations}

ERCP: endoscopic retrograde cholangiopancreatography

\section{References}

[1] Medarhri J., El Ounani M., Echarrab M., Louchi A., Alami F.,Amraoui M., Errogani A., Chkof R., Balafrej S. Les Kystes Hydatiques Du Foie Rompus Dans Les Voies Biliaires A Propos De 88 Cas Expérience Des Urgences Chirurgicales Viscérales - Rabat- Médecine du Maghreb 2001 n86 
[2] M. Daali, Y. Fakir, R. Hssaida, A. Hajji, A. Had. Les Kystes Hydatiques Du Foie Rompus Dans Les Voies Biliaires. À Propos De 64 Cas, Ann Chir $2001 ; 126: 242-5$

[3] Mountassir Moujahid \& Mohamed Tarik Tajdine. Les Kystes Hydatiques Du Foie Rompus Dans Les Voies Biliaires : A Propos De 120 Cas- Pan African Medical Journal. 2011

[4] Singh V, Reddy Dc, Verma Gr, Singh G. Endoscopic Management Of Intrabiliary-Ruptured Hepatic Hydatid Cyst. Liver International 2006: 26: 621-624

[5] Gaspare Galati, M.D.*, Antonio V. Sterpetti, M.D., F.R.C.S.(Engl), F.A.C.S., Maria Caputo, M.D., Marianna Adduci, M.D., Giorgio Lucandri, M.D., Stefania Brozzetti, M.D., Antonio Bolognese, M.D., Antonino Cavallaro, M.D., F.A.C.S. I Clinica Chirurgica Università Di Roma-La Sapienza, Rome, Italy Endoscopic Retrograde Cholangiography For Intrabiliary Rupture Of Hydatid Cyst, The American Journal of Surgery 191 (2006) 206-210

[6] Haliss, Ims, Ek, Md, Ersan Özaslan, Md, ’Iskender Sayek, Md, Cemil Savas, Md, Osman Abbasog ¿ Lu, Md, Ali Riza Soylu, Md,Yasemin Balaban, Md, Gonca Tatar, Md. Diagnostic And Therapeutic Ercp In Hepatic Hydatid Disease, GASTROINTESTINAL ENDOSCOPY VOLUME 58, NO. 3, 2003

[7] M.A.Al Karawi , M.I.Yasawy , A.R.Elshiekh. Endoscopic Management Of Biliary Hydatid Disease : Report On Six Cases Endoscopy23(1991) 278-281

[8] Murat Akaydin, Fazilet Erozgen, Yeliz E. Ersoy, Selim Birol, Rafet Kaplan. Treatment of hepatic hydatid disease complications using endoscopic retrograde cholangiopancreatography procedures; J can chir, Vol. 55, No 4, août 2012

[9] Alper Akcan, Erdogan Sozuer, Hizir Akyildiz, Ahmet Ozturk, Altay Atalay, Zeki Yilmaz. Predisposing Factors And Surgical Outcome Of Complicated Liver Hydatid Cysts. World J Gastroenterol 2010 June 28; 16(24): 3040-3048

[10] Mohamed Borahma \& Rajaa Afifi \& Imane Benelbarhdad \& Fatima Zahra Ajana \& Wafaa Essamri \& Abdellah Essaid. Early Recognition Of Post-Ercp Pancréatitis By Clinical Assessment And Serum Pancreatic Enzymes.Am J Gastroenterol 1996; 91:1553-7

[11] Hanane Massit1,\&, Hassan Seddik1, Hanane Basr1, Ahmed Benkirane. Traitement Endoscopique Des Complications Biliaires De L'hydatidose Hépatique. Pan African Medical Journal - ISSN: 1937- 8688

[12] O. Baraket*, M.N. Feki, M. Chaari, A. Saidani,M. Ben Moussa, M. Moussa, S. Bouchoucha. Hydatid Cyst Open In Biliary Tract: Therapeutic Approaches: Report Of 22 Cases, Journal de Chirurgie Viscérale, Volume 148, Issue 3, Pages 237-242

[13] Essat Asma. Les Kystes Hydatiques Du Foie Rompus Dans Les Voies Biliaires A Propos De 98 Cas Experience De La Clinique Chirurgicale A, Thèse De Médecine, Faculté De médecine Et De Pharmacie Rabat,2008 
[14] Gurkan Ozturk ,M. İlhan Yildirgan ;S.Selcuk Atamanalp ;Mahmut Başoğlu ;Bulent Aydinli ;K. Yalcın Polat ;Durkaya Oren ;Abdullah Kisaoğlu. An Algorithm for The Treatment of The Biliary Complications of Hepatic Hydatid Disease; Turk J Med Sci 2009; 39 (5): 671-685 